\title{
Experimental infection of immunocompetent and immunodeficient mice with Encephalitozoon cuniculi
}

\author{
Jiří Salát, Pavlína Braunfuchsová and Jan Kopecký
}

Institute of Parasitology, Academy of Sciences of the Czech Republic and Faculty of Biological Sciences, University of South Bohemia, Branišovská 31, 37005 České Budějovice, Czech Republic

Key words: microsporidia, Encephalitozoon cuniculi, SCID mice, NK cells

\begin{abstract}
An experimental infection with the microsporidian Encephalitozoon cuniculi Levaditi, Nicolau et Schoen, 1923 was studied using a model of immunocompetent BALB/c mice and immunodeficient SCID mice. The course of infection after intraperitoneal inoculation of $E$. cuniculi spores was evaluated using the presence of spores in peritoneal macrophages as a criterion. First significant decrease in the proportion of infected cells was recorded on day 9 post infection (p.i.) in BALB/c mice. From day 14 p.i. no spores were observed in macrophages from BALB/c mice, while the number of infected macrophages from SCID mice increased until the death of the mice. The natural killer (NK) cell activity of mouse splenocytes was compared with the production of interferon gamma (IFN- $\gamma$ ) by these cells. While in BALB/c mice NK activity peaked on days 9 and 14 p.i., in SCID mice the marked increase of NK activity was recorded close before death of mice, on day 21 p.i. in correlation with the production of IFN- $\gamma$. Production of specific antibodies was demonstrated from day 9 p.i. in sera from BALB/c mice. It is concluded that intraperitoneal infection of SCID mice with spores of E. cuniculi results in the marked increase in the number of peritoneal exudate cells and in the percentage of infected cells close before death of mice. Neither high activity of NK cells nor increased production of IFN- $\gamma$ are sufficient for the recovery of SCID mice from an E. cuniculi infection.
\end{abstract}

Microsporidia are obligate intracellular parasites that infect a wide range of invertebrates and vertebrates. They are characterised by a polar tube that is used to inject infective sporoplasm into the host cell. Microsporidia have been recognised as the causative agents of opportunistic infections in immunocompromised hosts, especially in patients with AIDS. Attention has been paid to several microsporidians observed in human diseases. Enterocytozoon bieneusi, the most common microsporidian observed in AIDS patients, causes diarrhoea (Canning and Hollister 1990). Encephalitozoon intestinalis and Encephalitozoon hellem are both associated with disseminated infection during HIV infection, as is Encephalitozoon cuniculi Levaditi, Nicolau et Schoen, 1923, which has been recently reported in immunocompromised patients (Soule et al. 1997, Weber et al. 1997).

Immunobiology of microsporidial infections has been mainly studied in the model infection of mice with Encephalitozoon cuniculi (Gannon 1980, Schmidt and Shadduck 1983, 1984, Koudela et al. 1993, Didier et al. 1995). This microsporidian infects endothelial and epithelial cells, fibroblasts and predominantly macrophages in a variety of mammals. It has been found in humans as well (Zender et al. 1989, Deplazes et al. 1996). In immunocompetent mice infected with $E$. cuniculi, latent infection remains asymptomatic as long as parasite multiplication and host immune response are balanced (Gannon 1980, Niederkorn et al. 1981). On the contrary, in immunocompromised hosts such as SCID or athymic mice, acute, potentially fatal disease develops after experimental infection (Schmidt and Shadduck 1983, Koudela et al. 1993).

Recently, host immunity against microsporidia has been widely studied. The role of both humoral and cellular immunity has been demonstrated. While the adoptive transfer of hyperimmune serum failed to protect athymic mice from a lethal E. cuniculi infection, sensitised syngeneic T-cell-enriched spleen cells provided a complete protection of athymic or SCID mice from this infection (Schmidt and Shadduck 1983, Heřmánek et al. 1993). Studies by Schmidt and Shadduck (1984) have shown that cytokines, released by sensitised $\mathrm{T}$ cells from E. cuniculi-infected mice, activate macrophages to kill E. cuniculi in vitro. As it has been shown by Didier et al. (1994), interferon gamma (IFN- $\gamma$ ) seems to be the most important among these cytokines. The significant role of IFN- $\gamma$ in cellular immune response against murine E. cuniculi infection has been confirmed recently using IFN- $\gamma$ gene knockout mice (Khan and Moretto 1999). The study of the cytokine response of immunocompetent BALB/c mice and immunodeficient SCID mice to infection with the E. cuniculi showed both Th1 and Th2 cytokine production in BALB/c mice and an alternative pathway of IFN- $\gamma$ production in SCID mice, probably by IL-12stimulated NK cells (Braunfuchsová et al. 1999).

Current studies emphasise an important role of cellular immune response in defence against E. cuniculi infection. In the study of the significance of individual T-cell subsets in immunity against this parasite, the 
essential role of CD8+ cytotoxic T lymphocytes (CTL) has been shown using gene knockout mice (Khan et al. 1999). Mice lacking CD8+ T cells were highly susceptible to microsporidial infection. Interestingly, a normal antigen-specific CD8+ T-cell response to E. cuniculi infection was observed in mice lacking CD4+ $\mathrm{T}$ lymphocytes. Thus this infection is an example of an intracellular parasitic infection where CD8 + T-cell immunity can be induced in the absence of $\mathrm{CD} 4+\mathrm{T}$ cells (Moretto et al. 2000).

The main objective of the present study was to compare the immune response of immunocompetent and immunodeficient hosts to E. cuniculi infection and to estimate the role of particular immune mechanisms in the protective immunity. We assessed the proliferation of the parasite in macrophages, activation of NK cells, the interferon-gamma and specific antibody response.

\section{MATERIALS AND METHODS}

Mice. BALB/c mice (Charles River WIGA, Sulzfeld, Germany) 7-9 weeks of age were fed standard diet and caged at controlled temperature $\left(22^{\circ} \mathrm{C}\right)$ and relative humidity $(65 \%)$. SCID mice of the BALB/c background (originally obtained from Dr. Bosma - Fox Chase Centre, Philadelphia, USA) were housed in flexible film isolators (BEM Znojmo, Czech Republic) with high-efficiency particulate air (HEPA) filters and supplied sterilised diet and water ad libitum. Mice aged 8 weeks at the moment of infection were used throughout the experiments.

Organisms. Encephalitozoon cuniculi, strain EC2 originally isolated from dexamethasone-treated laboratory mouse (Koudela et al. 1994), was grown in VERO E6 cells for provision of spores. Cells were cultivated in RPMI 1640 medium supplemented with $2.5 \%$ foetal calf serum (FCS). The spores were purified by centrifugation over $50 \%$ Percoll (Pharmacia), washed three times in deionised water and stored in deionised water with antibiotics $(100 \mathrm{U} / \mathrm{ml}$ penicillin, 100 $\mu \mathrm{l} / \mathrm{ml}$ streptomycin, $2.5 \mu \mathrm{g} / \mathrm{ml}$ amphotericin; Sigma). Before inoculation, the spores were washed in PBS.

Cell line. YAC-1 mouse lymphoma (A/Sn origin) cells were cultivated in RPMI 1640 medium (Sigma) supplemented with $10 \%$ FCS, $5 \times 10^{-5} \mathrm{M} 2$-mercaptoethanol and antibiotics.

Experimental protocol. Eighteen SCID and eighteen $\mathrm{BALB} / \mathrm{c}$ mice were injected intraperitoneally (i.p.) with $10^{7}$ spores of E. cuniculi. On days 1, 3, 5, 9, 14 and 21 post infection (p.i.), three mice of each strain were killed. Groups of three uninfected mice of both strains served as a control.

Mice were killed humanely and bled by a cardiac puncture. Individual sera were collected and stored at $-20^{\circ} \mathrm{C}$ until used for enzyme linked immunosorbent assay (ELISA). Peritoneal exudate cells (PEC) were recovered by lavaging the peritoneum with $2 \mathrm{ml}$ of cold RPMI 1640. PEC were washed and counted. Portion of PEC was stained with Calcofluor (Sigma) and observed with an Olympus IX 70 fluorescent microscope for detection of E. cuniculi spores. A suspension of spleen cells was generated in RPMI 1640 medium supplemented with $10 \% \mathrm{FCS}, 5 \times 10^{-5} \mathrm{M} 2$-mercaptoethanol and antibiotics and seeded into 96-well tissue culture plates (NUNC), $5 \times 10^{6}$ cells in $0.2 \mathrm{ml}$ per well. After 24 hours incubation at $37^{\circ} \mathrm{C}$ and $3.5 \% \quad \mathrm{CO}_{2}$, supernatants were harvested and stored at $-20^{\circ} \mathrm{C}$ for cytokine ELISA. A portion of splenocytes was used as effector cells in NK assay.

Detection of $\boldsymbol{E}$. cuniculi spores in macrophages. PEC were fixed with methanol for $2 \mathrm{~min}$ at room temperature and stained with $1 \%$ Calcofluor (Sigma) for $10 \mathrm{~min}$. After that the slides with PEC were washed in PBS and covered with $0.5 \%$ Evans blue in PBS for $30 \mathrm{~s}$. The slides were then washed in PBS and observed with an Olympus epifluorescent microscope with $425-\mathrm{nm}$ and 460-nm exciting and block filters, respectively. The number of spores in 100 cells and percentage of infected macrophages (distinguished by the size and shape) were assessed. The results represent the mean of three separate counts.

Measurement of interferon gamma (IFN- $\gamma$ ) production. Levels of IFN- $\gamma$ in cell culture supernatants were measured by capture enzyme-linked immunosorbent assay (ELISA), following the manufacturer's protocol. The following pair of rat anti-mouse cytokine monoclonal antibodies (MAbs) (PharMingen, San Diego, CA) were used in the assay: unconjugated $\mathrm{MAb}$ clone R4-6A2 and biotinylated MAb clone XMG1.2. Micro E.I.A./R.I.A. plates, flat bottom, high binding (Costar, Cambridge, MA) were coated with purified MAb (4 $\mu \mathrm{g} / \mathrm{ml}$ ) diluted with $0.1 \mathrm{M}$ sodium carbonate buffer $(\mathrm{pH} 8.2$ ). One hundred $\mu \mathrm{l}$ of diluted MAb, per well, were incubated overnight at $4^{\circ} \mathrm{C}$. After washing three times with $0.05 \%$ Tween 20 in PBS (T-PBS), unoccupied sites were blocked with $200 \mu$ of $10 \%$ newborn calf serum (NBCS) in PBS for one hour at room temperature. Plates were washed four times with T-PBS and incubated with cell culture supernatants overnight at $4{ }^{\circ} \mathrm{C}$. Biotinylated antibody $(2 \mu \mathrm{g} / \mathrm{ml}$ in PBS, $10 \%$ NBCS) was then added at $100 \mu \mathrm{l}$ per well and incubated for 45 min at room temperature. Plates were washed six times and $100 \mu \mathrm{l}$ streptavidin-peroxidase (Sigma) diluted 2400-fold in PBS with $10 \%$ NBCS was allowed to incubate for $30 \mathrm{~min}$ at room temperature. After washing eight times, an enzymatic colour reaction was generated using orthophenylenediamine substrate, stopped after 10 min with $100 \mu \mathrm{l}$ of $2 \mathrm{M} \mathrm{H}_{2} \mathrm{SO}_{4}$ and measured at $490 \mathrm{~nm}$ with an ELISA spectrophotometer (Labsystem Multiskan). Cytokine levels were determined from standard graphs generated from known quantities of recombinant IFN- $\gamma$ standard (PharMingen). Results represent the mean of three wells.

Serum antibody assay. To measure the relative levels of microsporidia-specific serum antibodies, a modified ELISA method described by Hollister and Canning (1987) was used. Tissue culture-derived E. cuniculi spores were adjusted to $1 \times$ $10^{7} / \mathrm{ml}$ in coating buffer and $100 \mu \mathrm{l}$ was added to each well of 96-well ELISA plates. The plates were incubated overnight at $4^{\circ} \mathrm{C}$. Then the plates were allowed to dry and they were fixed with a $1: 1$ mixture of acetone and methanol for $10 \mathrm{~min}$ at room temperature. After blocking the unbound sites with 5\% NBCS in PBS for one hour at $37^{\circ} \mathrm{C}$ the plates were washed with $0.05 \%$ T-PBS three times and incubated with test sera diluted $1: 100$ in $2 \%$ NBCS in PBS for one hour at $37^{\circ} \mathrm{C}$. The plates were then washed with T-PBS and incubated with peroxidase-conjugated swine anti-mouse IgG (Sevak, Prague, Czech Republic) diluted 1:2000 in 2\% NBCS in PBS for one hour at $37^{\circ} \mathrm{C}$. After washing, an enzymatic colour reaction was generated using orthophenylenediamine substrate, 
stopped after 10 min with $100 \mu \mathrm{l}$ of $2 \mathrm{M} \mathrm{H}_{2} \mathrm{SO}_{4}$ and measured as mentioned for cytokine ELISA. Results represent the mean of three wells.

NK cell assay. The activity of NK cells was determined using a test based on the release of ${ }^{51} \mathrm{Cr}$ from target YAC-1 cells. Briefly, $10^{6}$ YAC-1 cells were labelled with $50 \mu \mathrm{Ci}$ $\mathrm{Na}_{2}{ }^{51} \mathrm{CrO}_{4}$ (Amersham, UK) in RPMI 1640 at $37^{\circ} \mathrm{C}$ for one hour. The labelled target cells in RPMI 1640 supplemented with $10 \% \mathrm{FCS}, 2 \times 10^{-5} \mathrm{M}$ 2-mercaptoethanol and antibiotics were dispensed into microtitre plates (Nunclon, Denmark, U bottom), $10^{4}$ cells in $100 \mu \mathrm{l}$ per well. Into each well $10^{6}$ splenocytes, obtained from E. cuniculi-infected mice or control mice, were added in $100 \mu \mathrm{l}$ and the plates were centrifuged at $150 \times \mathrm{g}$ for $5 \mathrm{~min}$ and incubated at $37^{\circ} \mathrm{C}$ and $3.5 \% \mathrm{CO}_{2}$ for 5 hours. From each well $100 \mu \mathrm{l}$ of the medium was harvested and measured in a Gamaautomat (Tesla Liberec, Czech Republic). The percentage of specific ${ }^{51} \mathrm{Cr}$ release was calculated using the following formula: percentage of specific release $=(E R-S R) \times 100 / M R-S R$, where ER was experimental ${ }^{51} \mathrm{Cr}$ release, SR the spontaneous ${ }^{51} \mathrm{Cr}$ release as measured by incubating target cells in medium alone, and MR the maximum release after the addition of $100 \mu \mathrm{l}$ of $2 \%$ Triton X-100 instead of spleen cells. All determinations were made in triplicate; mean values were taken as an NK activity.

Statistical analysis. The significance of differences between experimental groups was evaluated by Student's $t$ test.

\section{RESULTS}

Intraperitoneal infection of SCID mice with $E$. cuniculi spores was accompanied by a marked increase in the absolute number of peritoneal exudate cells on days 14 and 21, soon before the death of mice (Fig. 1). In contrast, no significant changes in the number of peritoneal cells were observed in immunocompetent $\mathrm{BALB} / \mathrm{c}$ mice. The course of microsporidial infection of peritoneal macrophages was similar in both murine strains until day 9 p.i. After an increase in the percentage of macrophages containing spores on day 3 p.i. ( $18 \%$ of positive cells), the proportion of positive cells decreased in BALB/c mice to approximately $2 \%$ on day 9 p.i. and no positive cells were found in later intervals. In SCID mice, the transient increase of positive cells on day 3 p.i. was followed by a decline on days 5 and 9 p.i. The maximum proportion of macrophages containing spores was recorded on days 14 and 21, soon before the death of the mice. In these time intervals almost all macrophages were infected (Fig. 2). Similar results were obtained using another criterion: the number of spores per 100 macrophages (Fig. 3). The highest number of spores was recorded in the macrophages from BALB/c mice on day 3 p.i., followed by a decline, and no spores were observed on day 14 p.i. In SCID mice, 1500 spores per 100 macrophages were counted on day 14 p.i. and twice as many spores on day 21 , corresponding to 30 spores per macrophage. The spores were distributed all over the cell, Calcofluor staining did

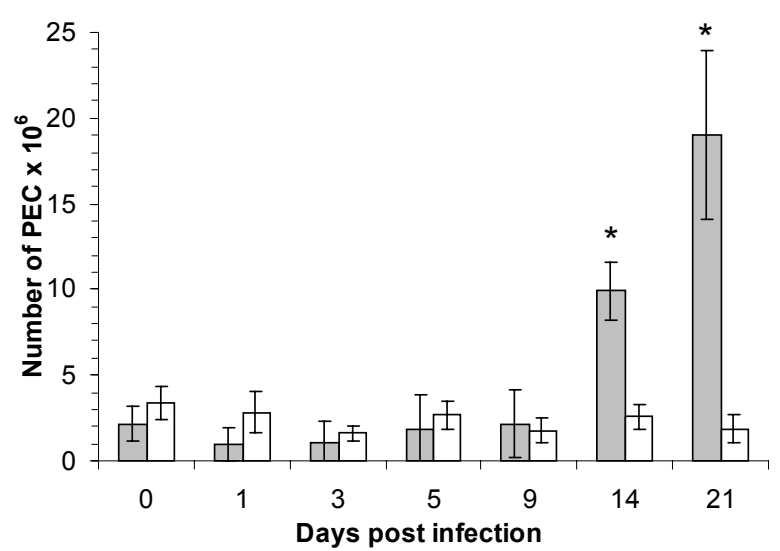

Fig. 1. Number of peritoneal exudate cells from $B A L B / c$ (open bars) and SCID (closed bars) mice post i.p. infection with $10^{7}$ Encephalitozoon cuniculi spores. Each column represents the mean of three mice $\pm \mathrm{SD}$. ${ }^{*}$ The numbers of PEC in SCID mice on days 14 and 21 were significantly different from the values on previous days at $\mathrm{P}<0.05$.

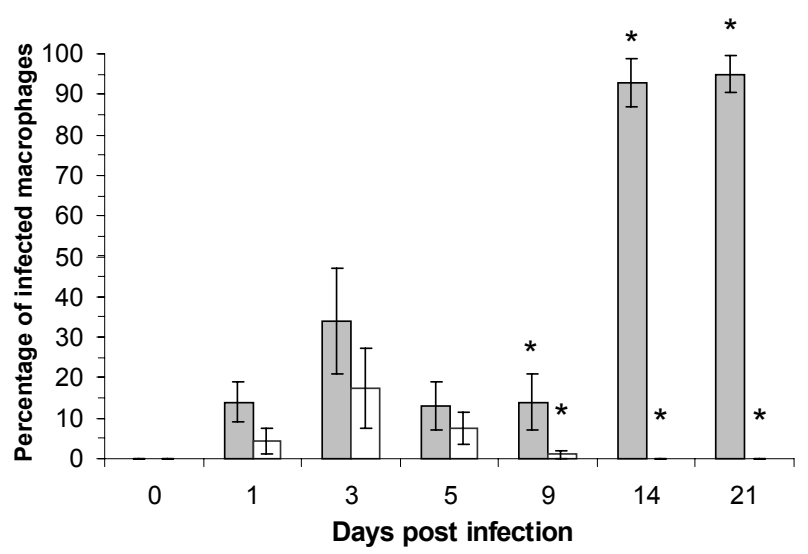

Fig. 2. Course of infection of macrophages from BALB/c (open bars) and SCID (closed bars) mice i.p. infected with $10^{7}$ Encephalitozoon cuniculi spores as estimated by the percentage of infected macrophages. Each column represents the mean of three mice $\pm \mathrm{SD}$. *The difference between BALB/c and SCID mice was significant at $\mathrm{P}<0.05$.

not indicate any germination of intracellular spores. Free spores were often observed in the peritoneal exudate smears.

Intraperitoneal infection with $E$. cuniculi resulted in markedly enhanced activity of NK cells in both murine strains. Duration and rate of $\mathrm{NK}$ activity differed between these strains. The maximum of NK cytotoxicity was recorded on day 9 p.i. in BALB/c mice (Fig. 4). At this time, $31 \%$ of specific ${ }^{51} \mathrm{Cr}$ release was measured. In SCID mice, the splenic NK activity decreased to the minimum on day 5 p.i., followed by an increase (Fig. 5). The highest cytotoxic activity $(26 \%)$ was recorded on day 21 p.i., close to the death of the mice. 


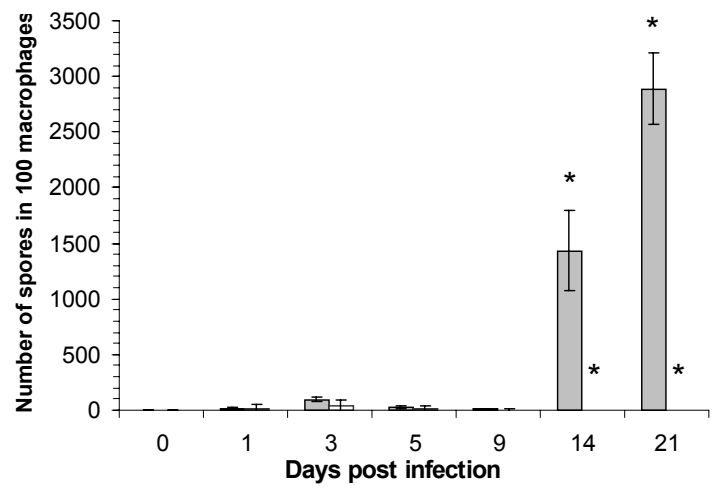

Fig. 3. Course of infection of macrophages from BALB/c (open bars) and SCID (closed bars) mice i.p. infected with $10^{7}$ Encephalitozoon cuniculi spores as estimated by the number of spores in 100 macrophages. Each column represents the mean of three mice $\pm \mathrm{SD}$. $*$ The difference between $\mathrm{BALB} / \mathrm{c}$ and SCID mice was significant at $\mathrm{P}<0.05$.

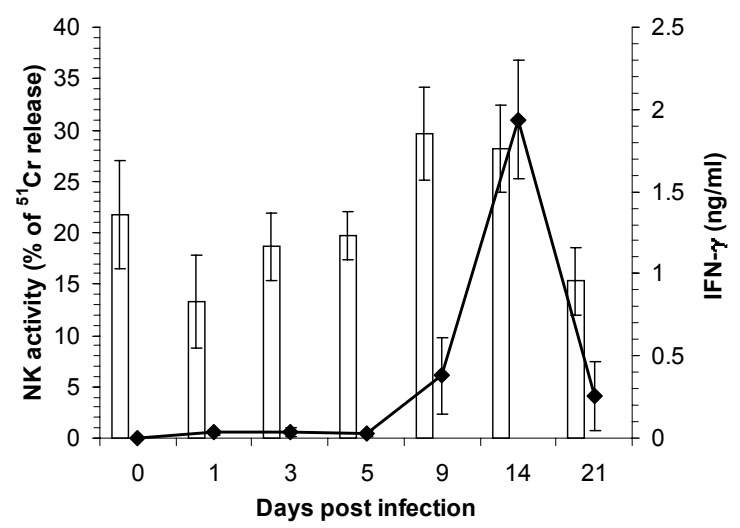

Fig. 4. NK activity (open bars) of splenocytes and levels of IFN- $\gamma$ (full line) in splenocyte cultures from BALB/c mice i.p. infected with $10^{7}$ Encephalitozoon cuniculi spores. Each value represents the mean of three measurements $\pm \mathrm{SD}$.

The maximum production of IFN $-\gamma, 1.9 \mathrm{ng} / \mathrm{ml}$, was measured on day 14 p.i. of BALB/c mice, 5 days after the maximum of NK activity was detected (Fig. 4). In SCID mice, IFN- $\gamma$ was determined in lower concentrations with the first maximum of $0.1 \mathrm{ng} / \mathrm{ml}$ on day 1 p.i. The second maximum of $0.7 \mathrm{ng} / \mathrm{ml}$ was recorded on day 21, at the time of the highest NK activity (Fig. 5).

Production of specific antibodies to E. cuniculi was demonstrated in sera of infected BALB/c mice from day 9 p.i., gradually increasing to the end of the experiment (Fig. 6). In sera of immunodeficient SCID mice, specific antibodies were not detected.

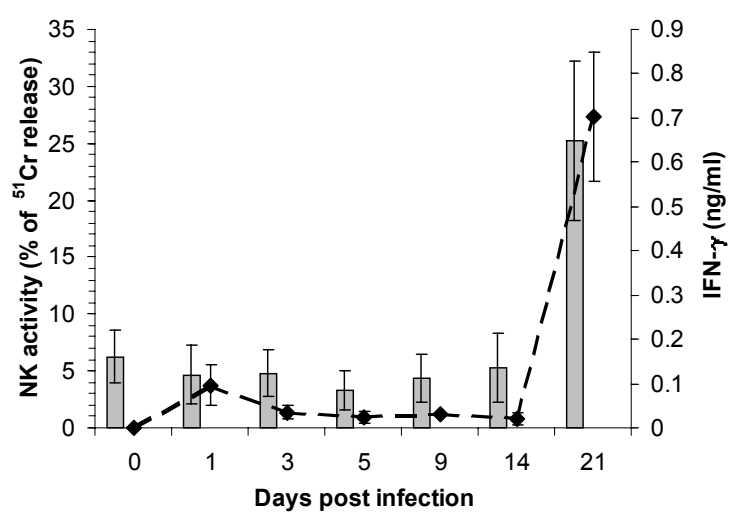

Fig. 5. NK activity (closed bars) of splenocytes and levels of IFN- $\gamma$ (dashed line) in splenocyte cultures from SCID mice i.p. infected with $10^{7}$ Encephalitozoon cuniculi spores. Each value represents the mean of three measurements \pm SD.

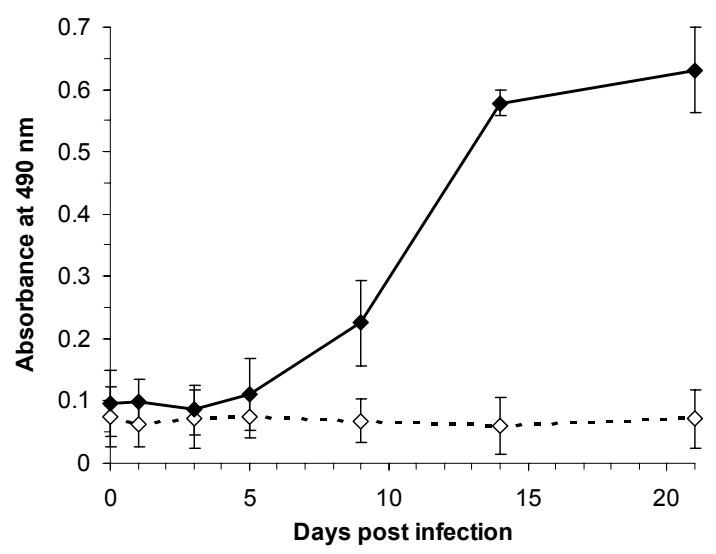

Fig. 6. Relative production of specific antibodies by BALB/c (full line) and SCID (dashed line) mice i.p. infected with $10^{7}$ Encephalitozoon cuniculi spores as determined in serum by ELISA. Each value represents the mean of triplicate wells \pm SD.

\section{DISCUSSION}

Encephalitozoon cuniculi is a common parasite of laboratory animals and recently is being recognised as an opportunistic pathogen in immunocompromised individuals, particularly in patients with AIDS (Deplazes et al. 1996). In immunocompetent mice, $E$. cuniculi infection rarely caused clinical disease. However, E. cuniculi-infected SCID mice developed fatal microsporidiosis. This study investigated replication of E. cuniculi and some parameters of immune response to the parasite in the model of immunocompetent $\mathrm{BALB} / \mathrm{c}$ mice and immunodeficient SCID mice. 
Intraperitoneal infection of $\mathrm{BALB} / \mathrm{c}$ mice did not significantly change absolute numbers of peritoneal exudate cells. Although the proportion of infected macrophages reached $17 \%$ on day 3 p.i., the antigenic stimulus was not strong enough to induce the recruitment of additional inflammatory cells into the peritoneal cavity. In SCID mice the marked influx of phagocytic cells into the peritoneum on days 14 and 21 p.i. correlated with an intensive replication of the parasite in these cells. At this time almost $100 \%$ of macrophages were infected, containing 30 spores per cell on average. It is likely that uncontrolled replication of the parasite in peritoneal cells produced a strong pro-inflammatory signal leading to the multiple increase in number of peritoneal cells. This increase again provided additional substrate for the parasite growth. Of several cytokines (IL-1, IL-6, IFN- $\gamma$ ) which can represent the proinflammatory signal, only the level of IFN- $\gamma$ was determined in the peritoneal fluid. IFN- $\gamma$ peaked on day 9 p.i. and declined to the zero level on day 14 p.i. (data not shown).

Replication of E. cuniculi in peritoneal macrophages is controlled by mechanisms of specific adaptive immunity. Among these mechanisms IFN- $\gamma$ plays a significant role. According to results by Didier et al. (1994), E. cuniculi is killed in IFN- $\gamma$-activated macrophages by nitric oxide-dependent mechanism. In vivo experiments, conducted by Khan and Moretto (1999), confirmed the crucial role of IFN- $\gamma$, which was however NO-independent. In our experiments in $\mathrm{BALB} / \mathrm{c}$ mice, the percentage of infected macrophages started to decline from day 3 p.i., long before an increase in IFN- $\gamma$ production by splenocytes was measurable. One explanation for the decrease of infected macrophages in the peritoneal cavity can be their escape to adjacent tissues and organs, contributing to dissemination of the infection. This idea is supported by the fact that similar decrease in the proportion of infected macrophages was recorded in SCID mice, where the mechanisms of specific adaptive immunity do not participate. In SCID mice, the increased production of IFN- $\gamma$ followed the increased replication of the parasite in macrophages.

From these results it can be concluded that further mechanisms (not available in SCID mice) seem to be necessary for the recovery from the E. cuniculi infection, even if the role of IFN- $\gamma$ can not be omitted. The recent data presented by Khan et al. (1999) and Braunfuchsová et al. (2001) emphasise the crucial role of CD8+ CTL in anti-microsporidial immunity.

In SCID mice the activity of NK cells correlated with the production of IFN- $\gamma$. Although it is well known that interferons activate NK cells, these cells can produce
IFN- $\gamma$ after induction by various stimuli (Kubota et al. 1999). From our data we can assume that NK cells were activated in some other way, for example by IL-12 produced by infected macrophages (Braunfuchsová et al. 1999). In BALB/c mice, in which IFN- $\gamma$ can be produced by Th1 lymphocytes in addition to NK cells, the clear correlation between NK activity and the production of IFN- $\gamma$ was not observed.

The role of NK cells in the protection of the host against E. cuniculi infection remains obscure. The cytotoxic activity of these cells in SCID mice is the highest soon before death of the mice. Moreover, the nonspecific cytotoxic activity of mouse splenocytes against E. cuniculi-infected macrophages (represented probably by NK cells) was higher against allogeneic than against syngeneic macrophages (Braunfuchsová et al. 2001). From this data it can be assumed that the role of NK cells in anti-microsporidial immunity is in the production of IFN- $\gamma$ and other cytokines rather than in their cytotoxic activity. Similar results were reported by Niederkorn et al. (1983), who recorded an increased NK activity in athymic nu/nu mice infected with $E$. cuniculi, but the mice succumbed to the infection.

The role of antibodies in the immune response to microsporidia also remains controversial. Transfer of hyperimmune serum to athymic mice infected with $E$. cuniculi failed to prolong their survival (Schmidt and Shadduck 1984). However, the recent work by Enriquez et al. (1998) has shown that preincubation of E. cuniculi spores with an anti-exospore monoclonal antibody significantly decreased the infectivity of spores for susceptible VERO E6 cells. In our experiments antimicrosporidial antibodies appeared in BALB/c mice on day 9 p.i., when the proportion of infected macrophages and content of spores had decreased to the minimum. Therefore it does not seem likely that antibodies themselves play a critical role in the protective immunity against E. cuniculi.

Our results show that in contrast to BALB/c mice, in which the infection was cured in first two weeks post infection, in SCID mice the number of PEC increased markedly on days 14 and 21 p.i., followed by the increase of the percentage of infected cells close before death of mice. NK cells apparently do not play a significant role in the protective immunity against $E$. cuniculi infection. Elucidation of the role of IFN- $\gamma$ needs further investigations.

Acknowledgements. The work was supported by grant A6022101 from the Grant Agency of the Academy of Sciences of the Czech Republic and grant 773/201 from the fund for Universities Development of the Ministry of Education, Youth and Sports of the Czech Republic. 


\section{REFERENCES}

BRAUNFUCHSOVÁ P., KOPECKÝ J., DITRICH O., KOUDELA B. 1999: Cytokine response to infection with the microsporidian Encephalitozoon cuniculi. Folia Parasitol. 46: 91-95.

BRAUNFUCHSOVÁ P., SALÁT J., KOPECKÝ J. 2001: CD8+ $\mathrm{T}$ lymphocytes protect SCID mice against Encephalitozoon cuniculi infection. Int. J. Parasitol. 31: 681-686.

CANNING E.U., HOLLISTER W.S. 1990: Enterocytozoon bieneusi (Microspora): prevalence and pathogenicity in AIDS patients. Trans. R. Soc. Trop. Med. Hyg. 84: 181186.

DEPLAZES P., MATHIS A., BAUMGARTNER R., TANNER I., WEBER R. 1996: Immunologic and molecular characteristics of Encephalitozoon-like microsporidia isolated from humans and rabbits indicate that Encephalitozoon cuniculi is a zoonotic parasite. Clin. Infect. Dis. 22: 557-559.

DIDIER E.S., VARNER P.W., DIDIER P.J., ALDRAS A.M., MILLICHAMP N.J., MURPHEY-CORB M., BOHM R., SHADDUCK J.A. 1994: Experimental microsporidiosis in immunocompetent and immunodeficient mice and monkeys. Folia Parasitol. 41: 1-11.

DIDIER E.S., VOSSBRINCK C.R., BAKER M.D., ROGERS L.B., BERTUCCI D.C., SHADDUCK J.A. 1995: Identification and characterization of three Encephalitozoon cuniculi strains. Parasitology 111: 411-422.

ENRIQUEZ F.J., WAGNER G., FARGOSO M., DITRICH O. 1998: Effects of an anti-exospore monoclonal antibody on microsporidial development in vitro. Parasitology 117: 515-520.

GANNON J. 1980: The course of infection of Encephalitozoon cuniculi in immunodeficient and immunocompetent mice. Lab. Anim. 14: 189-192.

HEŘMÁNEK J., KOUDELA B., KUČEROVÁ A., DITRICH O., TRÁVNÍČEK J. 1993: Prophylactic and therapeutic immune reconstitution of SCID mice infected with Encephalitozoon cuniculi. Folia Parasitol. 40: 287-291.

HOLLISTER W.S., CANNING E.U. 1987: An enzyme-linked immunosorbent assay (ELISA) for detection of antibodies to Encephalitozoon cuniculi and its use in determination of infection in man. Parasitology 94: 209-219.

KHAN I.A., MORETTO M. 1999: Role of gamma interferon in cellular immune response against murine Encephalitozoon cuniculi infection. Infect. Immun. 67: 1887-1893.

KHAN I.A., SCHWARTZMAN J.D., KASPER L.H., MORETTO M. 1999: CD8+ CTLs are essential for protective immunity against Encephalitozoon cuniculi infection. J. Immunol. 162: 6086-6091.
KOUDELA B., LOM J., VÍTOVEC J., KUČEROVÁ Z., DITRICH O., TRÁVNÍČEK J. 1994: In vivo efficacy of albendazole against Encephalitozoon cuniculi in SCID mice. J. Euk. Microbiol. 41: 49-50.

KOUDELA B., VÍTOVEC J., KUČEROVÁ Z., DITRICH O., TRÁVNÍČEK J. 1993: The severe combined immunodeficient mouse as model for Encephalitozoon cuniculi microsporidiosis. Folia Parasitol. 40: 279-286.

KUBOTA A., LIAN R.H., LOHWASSER S., SALCEDO M., TAKEI F. 1999: IFN-gamma production and cytotoxicity of IL-2-activated murine NK cells are differentially regulated by MHC class I molecules. J. Immunol. 163: 6488-6493.

LEVADITI C., NICOLAU S., SCHOEN R. 1923: Lagent étiologique de l'encéphalite épizootique du lapin (Encephalitozoon cuniculi). C. R. Soc. Biol. Paris. 89: 984-986.

MORETTO M., CASCIOTTI L., DURELL B., KHAN I.A. 2000: Lack of $\mathrm{CD}^{+} \mathrm{T}$ cells does not affect induction of $\mathrm{CD} 8^{+}$T-cell immunity against Encephalitozoon cuniculi infection. Infect. Immun. 68: 6223-6232.

NIEDERKORN J.Y., BRIELAND J.K., MAYHEW E. 1983: Enhanced natural killer activity in experimental murine encephalitozoonosis. Infect. Immun. 41: 302-307.

NIEDERKORN J.Y., SHADDUCK J.A., SCHMIDT E.C. 1981: Susceptibility of selected inbred strains of mice to Encephalitozoon cuniculi. J. Infect. Dis. 144: 246-253.

SCHMIDT E.C., SHADDUCK J.A. 1983: Murine encephalitozoonosis model for studying the host-parasite relationship of chronic infection. Infect. Immun. 40: 936-942.

SCHMIDT E.C., SHADDUCK J.A. 1984: Mechanisms of resistance to the intracellular protozoan Encephalitozoon cuniculi in mice. J. Immunol. 133: 2712-2719.

SOULE J.B., HALVERSON A.L., BECKER R.B., PISTOLE M.C., ORENSTEIN J.M. 1997: A patient with acquired immunodeficiency syndrome and untreated Encephalitozoon (Septata) intestinalis microsporidiosis leading to small bowel perforation. Response to albendazole. Arch. Pathol. Lab. Med. 121: 880-887.

WEBER R., DEPLAZES P., FLEPP M., MATHIS A., BAUMANN R., SAUER B., KUSTER H., LÜTHY R. 1997: Cerebral microsporidiosis due to Encephalitozoon cuniculi in a patient with human immunodeficient virus infection. N. Engl. J. Med. 336: 474-478.

ZENDER H.O., ARRIGONI E., ECKERT J., KAPANCI Y. 1989: A case of Encephalitozoon cuniculi peritonitis in a patient with AIDS. Am. J. Clin. Pathol. 92: 352-356. 